\title{
Neonatal apo A-I, apo B, and apo(a) Levels in Dried Blood Spots in an Australian Population
}

\author{
X. L. WANG, D. E. L. WILCKEN, AND N. P. B. DUDMAN \\ Department of Cardiovascular Medicine, University of New South Wales, Prince Henry/Prince of Wales \\ Hospitals, Sydney, New South Wales, Australia
}

\begin{abstract}
We measured neonatal apo A-I and apo B by ELISA, and apo(a) by RIA, in capillary blood spotted onto filter paper in samples also used for routine neonatal screening in $\mathbf{1 0 3 2}$ consecutively born babies. In the 2- to 5 -d-old babies with birth weights $\geq 2.0 \mathrm{~kg}(n=919)$, mean \pm SD levels of apo A-I and B were $0.48 \pm 0.19 \mathrm{~g} / \mathrm{L}$ and $0.24 \pm 0.14 \mathrm{~g} / \mathrm{L}$ of whole blood, respectively. The apo A-I levels were affected by birth weight (negatively) and by age at sampling (positively). The apo $B$ levels were affected positively by both variables, and girls had higher levels than boys $(p<0.01)$. These variables accounted for 3.5 and $6.2 \%$ of apo A-I and apo B variability, respectively ( $p$ $<0.001$ ). The apo(a) levels (mean $\pm \mathrm{SD}, 20 \pm 23 \mathrm{U} / \mathrm{L}$; median, $14 \mathrm{U} / \mathrm{L}, n=1032$ ) were unaffected by these factors. After adjustment for these variables, apo A-I levels were nearly normally distributed, whereas those of apo B were still positively skewed. The apo(a) distribution was strongly positively skewed and $1.2 \%$ of babies had levels above the equivalent of $25 \mathrm{mg} / \mathrm{dL}$ of lipoprotein(a) in serum. Our study shows that blood spots can be used to estimate apo A-I, apo B, and apo(a) levels in neonates, and establishes normal ranges. The results suggest that the apo(a) gene is expressed during the 1st postnatal week and that levels are independent of birth weight and apo A-I and $B$ concentrations. They also define the effects of birth weight and age at sampling on neonatal apo A-I and B levels. (Pediatr Res 28: 496-501, 1990)
\end{abstract}

Abbreviations

Lp(a), lipoprotein(a)

Carefully conducted studies over the past decades have demonstrated conclusively that atherogenesis begins in childhood (1). In cross-sectional studies, Stary (2) has documented a change from fatty streaks in infancy to fibrous plaques in young adulthood. In longitudinal studies, Berenson et al. (3) have elegantly described the changing lipid profile from infancy to adolescence and young adulthood. They also showed in young adults who died sudden accidental deaths a high correlation between antemortem LDL cholesterol levels and the extent of surface involvement of the aorta with fatty streaks (3); lesions in coronary arteries were inversely related to HDL cholesterol concentrations. There is now increasing evidence that high levels of apo $\mathrm{B}$, the carrier protein for the atherogenic LDL, and low levels of apo A-I, the principal carrier protein for the protective HDL, are

Received April 9, 1990; accepted June 13, 1990.

Correspondence: Professor D. E. L. Wilcken, Department of Cardiovascular Medicine, Clinical Sciences Building, The Prince Henry Hospital, Little Bay, N.S.W. 2036, Australia.

Supported by a grant from the National Heart Foundation of Australia. more predictive of cardiovascular risk than their respective lipoproteins (4).

$\mathrm{Lp}(\mathrm{a})$ is another lipoprotein for which high levels are independently associated with enhanced risk (5-7). Lp(a) particles are found in atheromatous plaques along with $\operatorname{LDL}(8,9)$. The $\mathrm{Lp}(\mathrm{a})$ particle contains apo(a) disulfide bound to apo $\mathrm{B}$, but is immunochemically distinct from LDL. The plasma concentration of $\mathrm{Lp}(\mathrm{a})$ in adults has a wide range, and is believed to be regulated by a series of codominant alleles for apo(a) at a single locus (10).

Recent clear documentation of the reduced cardiovascular risk associated with lowering elevated LDL cholesterol (11-15) has led to recommendations for population-based cholesterol measurements in adults (16-19). If children with a dominantly inherited disorder of lipid metabolism such as familial hypercholesterolemia and familial combined hyperlipoproteinemia could be identified before the occurrence of a premature vascular event in one of their parents, early intervention could be made available to the whole family.

For children, general screening of cholesterol is a controversial issue. Current recommendations of the Committee on Nutrition of the American Academy of Pediatrics are for cholesterol measurements only in children with a family history of premature cardiovascular disease (20). However, this approach has been recently shown to have a low sensitivity, and there are differing views on the strategy that should eventually be adopted (21). Dennison et al. (22) found that only $40 \%$ of the white children and $21 \%$ of the black children with elevated LDL cholesterol levels had a parental history of vascular disease. For community acceptance, screening procedures must provide accurate information and preferably identify a range of potential disorders in addition to being minimally intrusive. Our earlier studies explored screening for apo B only (23). The approach of our present study was to measure levels of apo A-I and apo(a) in addition to apo B in neonatal blood spots that are already available for screening for phenylketonuria and other inborn errors of metabolism.

\section{MATERIALS AND METHODS}

We studied 1032 neonates born consecutively between May and September 1989 at the Royal Hospital for Women in Sydney. At that hospital, a heel-prick blood sample was collected onto filter paper (newborn screening cards prepared from filter paper SS 2992, Schleicher and Schuell, Keene, NH) from each neonate, usually on d 3-5 after birth, as part of the New South Wales Department of Health neonatal screening program for phenylketonuria, hypothyroidism, cystic fibrosis, and galactosemia. The samples were air-dried and stored at $-20^{\circ} \mathrm{C}$ for $24 \mathrm{~h}$ and thereafter at $-70^{\circ} \mathrm{C}$ in our laboratory until assay. Levels of apo(a), A$\mathrm{I}$, and $\mathrm{B}$ were then measured within $2 \mathrm{wk}$ of collection. The protocol was approved by the Ethics Committee of the University of New South Wales.

Neonates. The mean age \pm SD of these 1032 neonates on the 
day of sampling was $4.25 \pm 0.98 \mathrm{~d}$ (range $1-10)$. However, most samples $(77 \%$ ) were collected 4 or $5 \mathrm{~d}$ after birth and only $5 \%$ of the neonates were sampled either before $\mathrm{d} 2$ or after $\mathrm{d} 7$. The mean \pm SD birth weight of the 1032 neonates was $3.29 \pm 0.64$ $\mathrm{kg}$, (range $0.6-4.9 \mathrm{~kg}$ ). In $86 \%$ of the neonates, birth weights were 2.0 to $4.0 \mathrm{~kg}$; only five neonates weighed less than $1.0 \mathrm{~kg}$ at birth, $3.5 \%$ of all neonates were between 1.0 and $2.0 \mathrm{~kg}$, and $9.9 \%$ were above $4.0 \mathrm{~kg}$. Neonates whose birth weights were below $1.0 \mathrm{~kg}$ tended to be sampled on later days after birth, and neonates with birth weights above $4.0 \mathrm{~kg}$ tended to be sampled early (Table 1). When least squares linear regression analysis was used to assess birth weight and age at sampling, the correlation coefficient was $0.135(p<0.0001)$.

There were 512 girls and 520 boys. The mean age at sampling was $4.2 \mathrm{~d}$ for both girls and boys. As expected, the mean \pm SD birth weight in girls $(3.22 \pm 0.62 \mathrm{~kg})$ was significantly lower than that in boys $(3.35 \pm 0.64 \mathrm{~kg} ; p<0.0001)$. After excluding 113 low-birth-weight and late-sampled neonates (see Results), there were 450 girls and 469 boys. The mean \pm SD birth weight for girls $(3.304 \pm 0.486 \mathrm{~kg})$ was still significantly lower than that for boys $(3.370 \pm 0.503 \mathrm{~kg} ; p<0.001)$. The mean age remained the same, $4.2 \mathrm{~d}$ for both girls and boys.

Parents were informed of the study, which was approved by the Ethics Committee of the University of New South Wales, and none declined to have their baby's samples tested.

apo A-I and apo B assays. We measured blood spot apo A-I and apo B levels by ELISA as described by us previously (24, 25). Calibration apolipoprotein serum (Boehringer-Mannheim, Mannheim, F.R.G.), which we made up in the form of dried blood spots, was used for the calibration curve. Quality control blood spots for each assay were prepared from lyophilized pooled serum provided by the Center for Disease Control (CDC, Atlanta, GA) and control serum (Behring Diagnostics, Behringwerke AG, Marburg, F.R.G.). All reported apo A-I and apo B levels were determined using CDC apo A-I and apo B reference material (CDC 1883) as primary standards. Only one batch of calibration and quality control dried blood spots was prepared and used throughout the study. The dried blood spots were stored at $-70^{\circ} \mathrm{C}$ in sealed plastic bags until assayed.

For the validation of the dried blood spot apo A-I assay, we measured apo A-I levels of simultaneously collected finger-prick blood spotted onto filter paper, venous blood spots, and venous sera from 20 adult subjects. The apo B levels of simultaneously collected venous blood spots and sera from 11 subjects were also determined to assess the validity of the dried blood spot apo B assay. We have previously shown a close correlation between simultaneously obtained capillary and venous blood spot apo B levels (26). All samples were stored at $-70^{\circ} \mathrm{C}$ before assay.

apo(a) assay. To measure dried blood spot apo(a) levels, we modified an RIA serum assay for apo(a) (Pharmacia Diagnostics

Table 1. Comparison of neonatal apo(a), apo A-I, and apo B levels, ratio of apo B/A-I, and birth wt with age at sampling*

\begin{tabular}{|c|c|c|c|c|c|}
\hline $\begin{array}{c}\text { Age of } \\
\text { sampling }\end{array}$ & $\begin{array}{l}\text { apo(a) } \\
(\mathrm{U} / \mathrm{L})\end{array}$ & $\begin{array}{c}\text { apo A-I } \\
(\mathrm{g} / \mathrm{L})\end{array}$ & $\begin{array}{c}\text { apo B } \\
(\mathrm{g} / \mathrm{L})\end{array}$ & $\begin{array}{l}\text { Ratio of } \\
\text { apo B/A-I }\end{array}$ & Birth wt \\
\hline $\begin{array}{c}\text { D } 2 \\
(n=29)\end{array}$ & $21 \pm 19$ & $0.37 \pm 0.12$ & $0.20 \pm 0.15$ & $0.68 \pm 0.86$ & $3.4 \pm 0.6$ \\
\hline $\begin{array}{c}\text { D } 3 \\
(n=151)\end{array}$ & $19 \pm 19$ & $0.44 \pm 0.19$ & $0.19 \pm 0.14$ & $0.52 \pm 0.86$ & $3.2 \pm 0.6$ \\
\hline $\begin{array}{c}\mathrm{D} 4 \\
(n=459)\end{array}$ & $21 \pm 24$ & $0.47 \pm 0.18$ & $0.24 \pm 0.13$ & $0.58 \pm 0.42$ & $3.4 \pm 0.6$ \\
\hline $\begin{array}{c}\text { D } 5 \\
(n=341)\end{array}$ & $20 \pm 23$ & $0.49 \pm 0.18$ & $0.26 \pm 0.15$ & $0.64 \pm 0.51$ & $3.3 \pm 0.6$ \\
\hline $\begin{array}{c}\mathrm{D} 6 \\
(n=30)\end{array}$ & $24 \pm 27$ & $0.52 \pm 0.26$ & $0.25 \pm 0.15$ & $0.65 \pm 0.54$ & $2.7 \pm 1.2$ \\
\hline $\begin{array}{c}\mathrm{D} 7 \\
(n=22)\end{array}$ & $23 \pm 24$ & $0.63 \pm 0.27$ & $0.20 \pm 0.13$ & $0.36 \pm 0.24$ & $2.7 \pm 0.8$ \\
\hline
\end{tabular}

* Babies sampled on postnatal d 6 and 7 had significantly lower birth wt. Results presented as mean $\pm \mathrm{SD}$.
AB, Uppsala, Sweden) as follows. Three 3-mm diameter blood discs were cut from each dried blood sample and transferred to a polystyrene test tube. Twenty $\mu \mathrm{L}$ of Tween- 20 buffer $(5 \mathrm{~g} / \mathrm{L}$ Tween-20 in PBS, pH 7.4) were then added to the discs to facilitate the elution of apo(a). After incubation for an hour, 20 $\mu \mathrm{L}$ of pretreatment buffer (Pharmacia Diagnostics) was added to the soaked discs, which were then incubated for another hour to pretreat the apo(a) in the eluate. The pretreated eluate was then diluted by $60 \mu \mathrm{L}$ of diluent (Pharmacia Diagnostics) and transferred to a fresh tube to react with antibody solution. The antibody solution was prepared by mixing an equal volume of ${ }^{125}$ I-labeled monoclonal anti-apo(a) antibody solution with another unlabeled monoclonal anti-apo(a) antibody solution. These two MAb bind to different epitopes on the apo(a) molecule (27). The reaction was carried out at room temperature for $1 \mathrm{~h}$. The antigen-antibody complexes were then precipitated by precipitation buffer (Pharmacia Diagnostics). The precipitin was separated from the supernatant by centrifugation, and the radioactivity of the precipitin was counted by gamma counter.

The blood spot apo(a) concentrations were read off the linearlogarithmic dried blood spot calibration curve. The calibration dried blood spots $(16-815 \mathrm{U} / \mathrm{L})$ were manufactured by diluting pooled apo(a) serum solutions with $5 \%$ BSA in PBS containing PBS-washed fresh human red blood cells. These standard mixtures were then pipetted onto filter paper and air-dried before they were stored at $-70^{\circ} \mathrm{C}$. The apo(a) concentration of the pooled serum was determined in four separate serum apo(a) assays in quadruplicate in each assay, and expressed in Pharmacia units, i.e. $\mathrm{U} / \mathrm{L}$, which is equivalent to $\mathrm{mg} / \mathrm{L}$. Aliquots of each of two apo(a) control serum solutions included in the Pharmacia serum RIA kit were mixed with equal volumes of fresh human blood red cells and used to prepare quality control dried blood spots. The apo(a) levels of these two control blood spots were $336 \pm 23$ and $103 \pm 6 \mathrm{U} / \mathrm{L}$ of whole blood, calculated from Pharmacia product information. Only one batch of calibration and control dried blood spots was prepared and used throughout the study. The calibration and control spots were treated and assayed in exactly the same way as the sample spots. The mean $\pm \mathrm{SD}$ within-assay coefficient of variation was $4.1 \pm 0.3 \%$, which was obtained from 40 blood spot samples assayed in duplicate with apo(a) concentrations ranging from 10 to $512 \mathrm{U} / \mathrm{L}$ of whole blood. Between-assay variations were monitored by assaying control blood spot samples in each assay of a total of 10 assays. The between-assay coefficient of variation was $4.7 \%$ for the control at $336 \mathrm{U} / \mathrm{L}$ of apo(a) and $4.3 \%$ for the control at 103 $\mathrm{U} / \mathrm{L}$ of apo(a).

To determine whether the dried blood spot apo(a) level reflects accurately the corresponding serum apo(a) level, we assayed apo(a) concentrations in 39 simultaneously collected venous dried blood spot and venous serum samples. These samples were collected from children and adults aged from 2 mo to $65 \mathrm{y}$. All samples were stored at $-70^{\circ} \mathrm{C}$ before the assay.

Relationship between apolipoprotein levels and other variables. Because our earlier studies had shown that neonatal apo B levels were affected by birth weight, age at sampling, and sex, we assessed the effects of these variables on the levels of the three apolipoproteins measured.

Statistics. The mean $( \pm \mathrm{SD})$ and median levels were calculated for each variable measured in the 1032 babies. Skewness and kurtosis were calculated to assess the normality of the frequency distributions of the apolipoprotein levels and the appropriateness of statistical methods for comparisons. The $t$ test after log transformation was used for comparison of apo(a) and apo B levels in different age, sex, and birth weight groups. The $t$ test was used for the comparison of apo A-I levels, in relation to birth weight, sex, and age of sampling. Analysis of variance ( $F$ test) was also used in the comparison of these variables among the subgroups.

To quantitate the effects of the independent baby-related variables, we assessed age at sampling, birth weight, and sex by partial multiple linear regression analysis with apo(a), apo A-I, 
and apo $\mathrm{B}$ as dependent variables. The percent variation in each of the dependent variables, apo(a), A-I, and B, that could be attributed to each independent variable was obtained by determining the square of the multiple regression coefficient $R$ and multiplying this by 100 . To adjust each individual baby's measured apo A-I and B values for the effects of birth weight, sex, and age at sampling, we calculated a "residual" value for apo A$\mathrm{I}$ and $\mathrm{B}$ for each baby and added this to the apo A-I and B population means. The residuals were obtained by subtracting expected levels of the dependent variables apo A-I and B from their actual measured values. The expected levels, in turn, were calculated by multiple regression equations, incorporating the independent variables birth weight, sex, and age at sampling (see Results).

\section{RESULTS}

Validation of dried blood spot apo(a), A-I, and B assays. Apolipoprotein levels measured in dried blood spots reflected accurately the corresponding serum levels. The correlation coefficients for apo(a), apo A-I, and apo B were $0.97,0.90$, and 0.89 , respectively, and this is shown for apo(a) in Figure 1. The fingerprick capillary dried blood spot apo A-I levels were also highly associated with both venous dried blood spot $(r=0.91 ; p<$ $0.0001)$ and venous serum apo A-I levels $(r=0.90 ; p<0.0001)$. These findings, together with our earlier ones for apo B (26), establish that capillary blood spotted onto filter paper can be used for the estimation of venous blood apolipoprotein levels.

Frequency distributions of apo(a), $A-I$, and $B$. The frequency distribution of blood apo(a) levels obtained from all 1032 neonates tested is shown in Figure 2 . This is very positively skewed, with a high proportion of neonates $(25 \%)$ having no detectable apo(a) in their dried blood spot samples. The mean \pm SD apo(a) blood level was $20 \pm 23 \mathrm{U} / \mathrm{L}$ of whole blood. The median apo(a) value was $14 \mathrm{U} / \mathrm{L}$. In contrast, after the correction of babyrelated factors and excluding 113 premature neonates the distribution of blood apo A-I levels was almost normal in these 919 neonates (Fig. 3). The mean blood apo A-I level $\pm \mathrm{SD}$ was 0.48 $\pm 0.19 \mathrm{~g} / \mathrm{L}$ of whole blood, and the median level was $0.45 \mathrm{~g} / \mathrm{L}$. The frequency distribution of the "corrected" blood spot apo B levels in these 919 neonates is shown in Figure 4, and was more positively skewed than that for blood apo A-I levels. The mean blood apo B level \pm SD was $0.24 \pm 0.14 \mathrm{~g} / \mathrm{L}$ of whole blood and the median level was $0.20 \mathrm{~g} / \mathrm{L}$. All neonates had measurable blood apo B values from their dried blood spot samples. When we assessed the distribution of apo B/apo A-I ratios, the pattern was also highly positively skewed (Fig. 5). The mean \pm SD

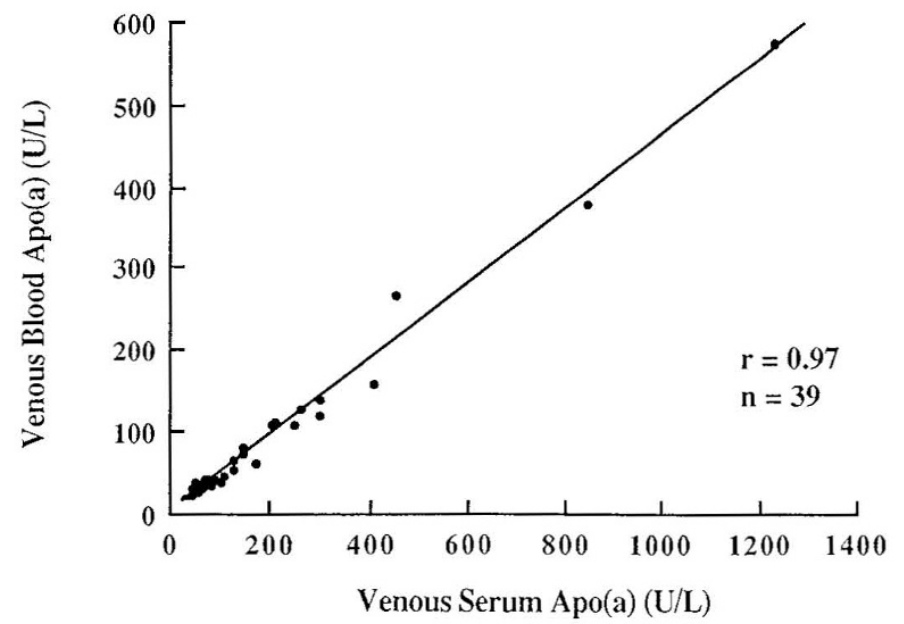

Fig. 1. Correlation between venous dried blood spot and venous serum apo(a) levels by least squares linear regression analysis in 39 subjects. The slope and intercept of the regression are 0.986 and -3.69 . The correlation coefficient is 0.97 . With the two highest values excluded, the correlation coefficient remains high at 0.94 .

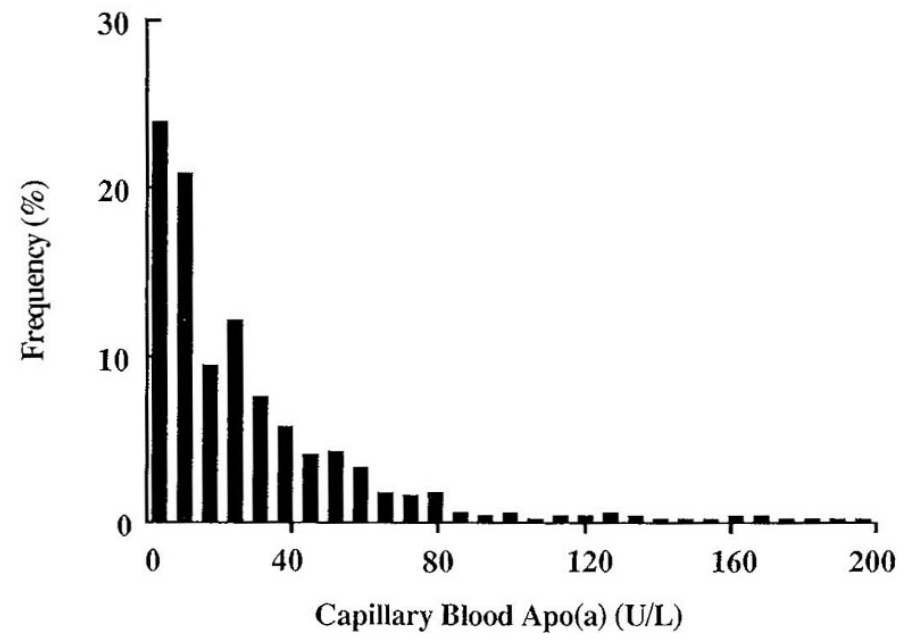

Fig. 2. The frequency distribution of capillary blood apo(a) levels in 1032 neonates, which is strongly positively skewed. The mean \pm SD and median levels of capillary blood apo(a) are $20 \pm 23 \mathrm{U} / \mathrm{L}$ and $14 \mathrm{U} / \mathrm{L}$.

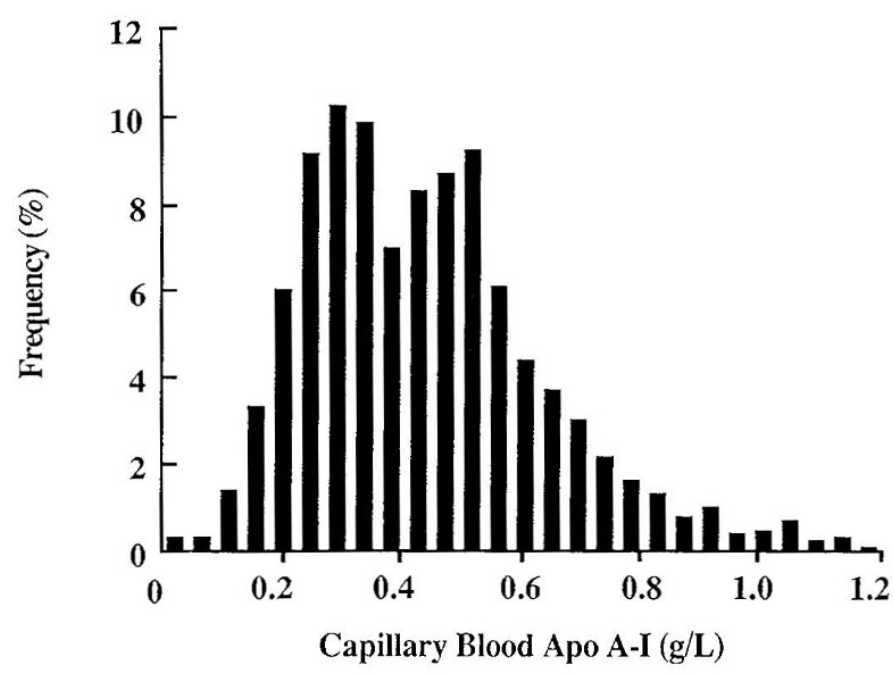

Fig. 3. The frequency distribution of capillary blood apo A-I levels in 919 neonates of birth weights $\geq 2.0 \mathrm{~kg}$, sampled on d 2 to 5 after birth. Values were corrected for baby-related factors by the regression equation: apo A-I $(\mathrm{g} / \mathrm{L})=-0.0249$ birth wt $(\mathrm{kg})+0.0356$ day of sampling $(\mathrm{d})-$ 0.0191 sex $(1$ or 2$)+0.400$. Female sex was counted as 1 and male sex was counted as 2 . The mean \pm SD and median apo A-I levels are 0.48 $\pm 0.19 \mathrm{~g} / \mathrm{L}$ and $0.45 \mathrm{~g} / \mathrm{L}$.

apo B/apo A-I ratio was $0.59 \pm 0.48$, and the median was 0.46 . But none of these distributions was skewed as much as was the distribution of blood apo(a) levels. The frequency distribution of blood apo(a) levels in these 919 neonates was in the same pattern as that for the 1032 neonates (Fig. 2).

Sex differences. The mean apo(a) levels for girls $(n=512)$ and boys $(n=520)$ were the same at $20 \pm 23 \mathrm{U} / \mathrm{L}$ of whole blood. The median apo(a) level in girls $(15 \mathrm{U} / \mathrm{L})$ was $2 \mathrm{U} / \mathrm{L}$ higher than that in boys $(13 \mathrm{U} / \mathrm{L})$, but the difference was not statistically significant. The mean apo A-I level \pm SD of $0.49 \pm 0.19 \mathrm{~g} / \mathrm{L}$ in girls $(n=450)$ was $4 \%$ higher than that in boys $(0.47 \pm 0.18$ $\mathrm{g} / \mathrm{L}, n=469$ ) but not significantly so by both $t$ test and $F$ test. Comparison of medians between girls $(0.46 \mathrm{~g} / \mathrm{L})$ and boys $(0.44$ $\mathrm{g} / \mathrm{L}$ ) also did not show a significant difference by nonparametric testing. However, blood apo B levels in girls $(n=459)$ were significantly higher than in boys $(n=469 ; p<0.01)$, and this was consistently so in each birth weight group (Fig. 6). The median levels in girls $(0.22 \mathrm{~g} / \mathrm{L})$ and in boys $(0.20 \mathrm{~g} / \mathrm{L})$ were not significantly different. Large variations in the apo B/apo A-I ratios were observed in both girls $(0.62 \pm 0.52, n=450)$ and 


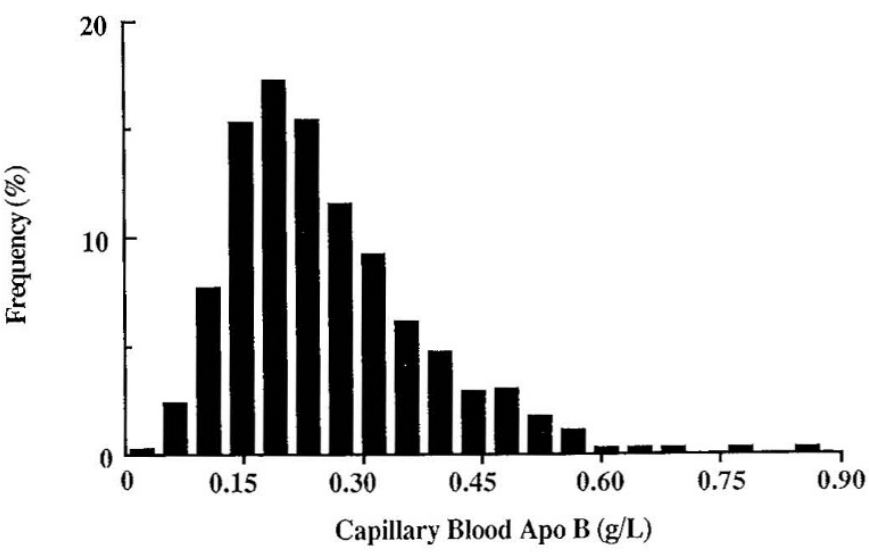

Fig. 4. The frequency distribution of capillary blood apo B levels in 919 neonates of birth weights $\geq 2.0 \mathrm{~kg}$, sampled on d 2 to 5 after birth. Values were corrected for baby-related factors by the regression equation: apo $B(g / L)=0.0363$ birth $w t(k g)+0.0319$ day of sampling $(d)-0.021$ sex $(1$ or 2$)-0.0138$. Female sex was counted as 1 and male sex was counted as 2 . The mean \pm SD and median apo B levels are $0.24 \pm 0.14$ $\mathrm{g} / \mathrm{L}$ and $0.20 \mathrm{~g} / \mathrm{L}$ and the distribution is positively skewed.

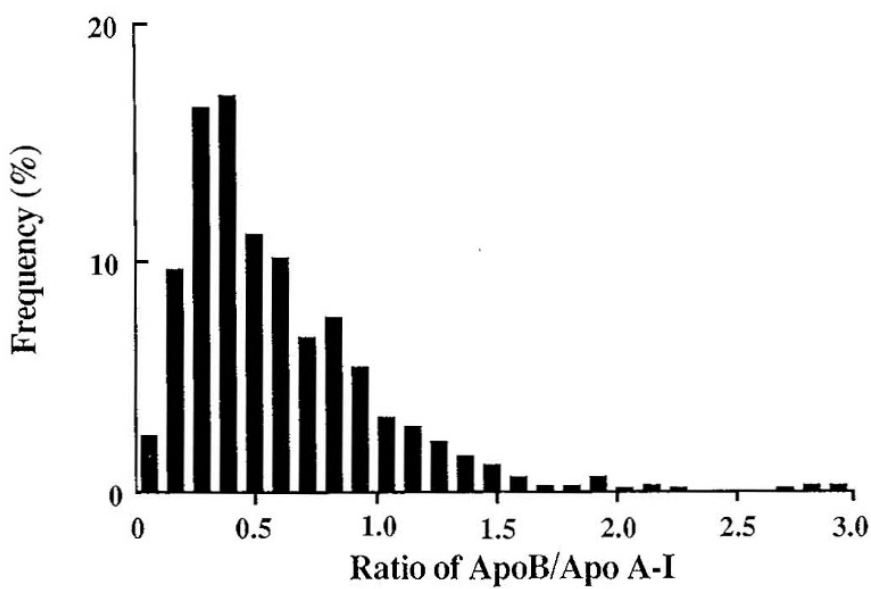

Fig. 5. The frequency distribution of the ratios of capillary blood apo B/apo A-I for the 919 neonates included in Figures 3 and 4. The mean \pm SD and median ratios are $0.59 \pm 0.48$ and 0.46 and the distribution is strongly positively skewed.

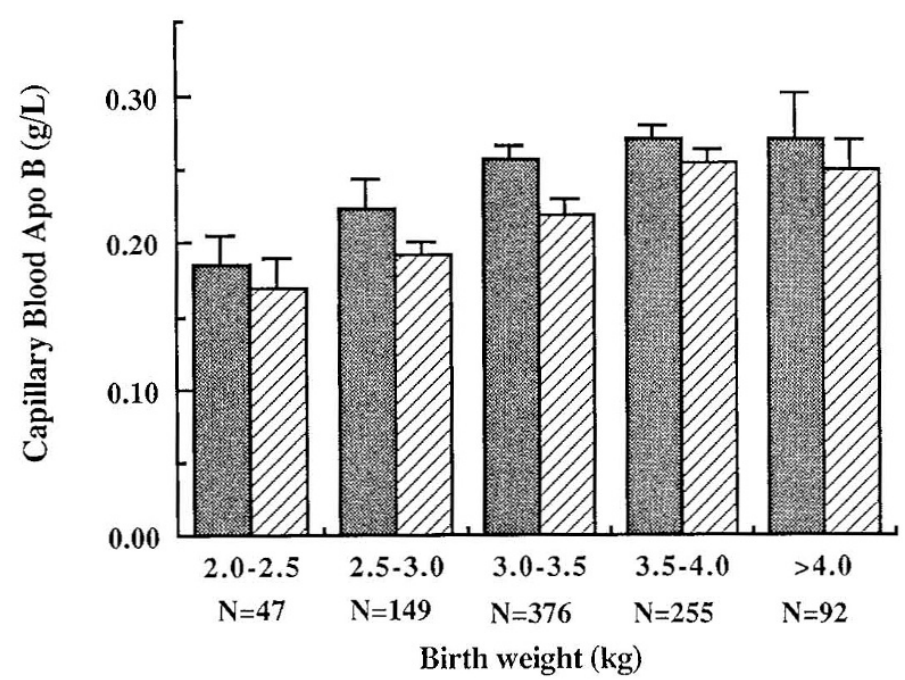

Fig. 6. Comparison of capillary blood apo B levels between girls and boys in different birth weight groups. The hatched bars refer to apo B levels in boys (mean \pm SEM), and the dot-filled bars to levels in girls. boys $(0.57 \pm 0.43, n=469)$, and the difference was not statistically significant. The median ratios in girls and boys were 0.47 and 0.44 , respectively.

Influence of birth weight and day of sampling of apo(a), A-I, and $B$ levels. Blood apo(a) levels of all 1032 babies were not systematically influenced by birth weight (Table 2) or day of sampling (Table 1), or by both of these variables together. Linear regression analysis with apo(a) level as the dependent variable and birth weight and day of sampling as independent variables either separately or together showed that $R^{2}$ between apo(a) and age was 0.0002 , between apo(a) and birth weight was 0.006 , and between apo(a) and birth weight and age was 0.006 .

By contrast, apo A-I levels were clearly affected by both day of sampling and birth weight. When apo A-I levels were regressed on birth weight and day of sampling separately as shown in Table 1 , apo A-I levels were positively associated with the day of sampling $(r=0.17, n=1032, p<0.0001)$ with $R^{2}$ at 0.029 , but as shown in Table 1 , negatively correlated with birth weight $(r=$ $-0.11, n=1032, p<0.001$ ) with $R^{2}$ at 0.012 . Using partial multiple regression analysis, these two independent variables still significantly influenced apo A-I levels with multi- $R^{2}$ at $0.041(n$ $=1032, p<0.001$ ). Thus, birth weight and day of sampling together contributed $4.1 \%$ of the variability of blood apo A-I levels; birth weight accounted for $1.2 \%$ and day of sampling, $2.9 \%$.

Blood apo B levels of these 1032 neonates were positively associated with both birth weight (Table 2) and day of sampling (Table 1). This association was also significant when both of the variables were considered together. The partial multiple regression analysis indicated that birth weight and day of sampling contributed $4.8 \%$ of the variability in apo B levels with birth weight accounting for $4.0 \%$ and day of sampling $0.8 \%$ $(n=1032)$.

Adjusted individual apo A-I and apo B levels. Because blood apo A-I and B levels were clearly influenced by both birth weight and day of sampling, we controlled for these variables to facilitate direct comparisons between babies. There was no need to adjust individual apo(a) level for these two independent variables, inasmuch as we had not found any significant associations.

When considering the birth weight and day of sampling data for all 1032 neonates shown in Table 1, it is apparent that there are two populations, those sampled on $\mathrm{d} 2$ to 5 and those sampled later. The latter group contained largely premature babies and infants with an abnormal postnatal course. Because apo A-I and apo B levels were significantly affected by birth weight and age at sampling, to minimize confounding effects from this relatively small subset we confined our analysis of apo A-I and apo B to neonates whose birth weights were above $2.0 \mathrm{~kg}$ and whose blood spot samples were taken on $\mathrm{d} 2$ to 5 inclusive after birth. There were 919 neonates who satisfied these criteria. Levels of apo A-I or apo B as dependent variables were regressed on birth weight day of sampling, and sex as independent variables by partial

Table 2. Birth wt compared with neonatal apo(a), apo A-I, and apo $B$ levels, ratio of apo $B / A-I$, and age at sampling*

\begin{tabular}{|c|c|c|c|c|c|}
\hline $\begin{array}{l}\text { Birth wt } \\
(\mathrm{kg})\end{array}$ & $\begin{array}{l}\text { apo(a) } \\
(\mathrm{U} / \mathrm{L})\end{array}$ & $\begin{array}{c}\text { apo A-I } \\
(\mathrm{g} / \mathrm{L})\end{array}$ & & $\begin{array}{c}\text { Ratio of } \\
\text { apo B/A-I }\end{array}$ & $\begin{array}{c}\text { Age at } \\
\text { sampling }\end{array}$ \\
\hline & & & $0.27 \pm$ & $0.71 \pm 0.44$ & $5.2 \pm$ \\
\hline & & & & & \\
\hline & & & & & \\
\hline $\begin{array}{l}3.0-4.0 \\
n=668)\end{array}$ & & $0.47 \pm 0.18$ & $0.25 \pm$ & & \\
\hline $\begin{array}{c}>4.0 \\
(n=102)\end{array}$ & $21.3 \pm 25$ & $0.46 \pm 0.19$ & $0.27 \pm 0.18$ & $0.68 \pm 0.56$ & \\
\hline
\end{tabular}

* Sampling tended to be delayed in babies with birth wt under $2.0 \mathrm{~kg}$. Results presented as mean \pm SD. 
multiple regression analysis. Female sex was counted as 1 and male as 2 . In these 919 babies, apo A-I levels were still influenced by birth weight and day of sampling, and these variables accounted for $3.5 \%$ of apo A-I variability. The apo B levels were also affected by all three independent variables, and they accounted for $6.2 \%$ of the variability in blood apo B levels. The apo A-I level of each individual neonate was adjusted by the regression equation:

apo A-I $(\mathrm{g} / \mathrm{L})=-0.0249$ birth $w \mathrm{t}(\mathrm{kg})+0.0356$ day of sampling $(d)-0.0191$ sex $(1$ or 2$)+0.400$

The apo $B$ level of each individual neonate was adjusted by the regression equation:

apo $\mathrm{B}(\mathrm{g} / \mathrm{L})=0.0363$ birth wt $(\mathrm{kg})+0.0319$ day of

$$
\text { sampling }(\mathrm{d})-0.021 \text { sex }(1 \text { or } 2)-0.0138
$$

From these "expected" levels, a "residual" value was obtained by subtracting the expected value from the measured value (see Materials and Methods).

Clustering of apolipoprotein levels. After adjusting the individual apo A-I and apo B levels for the baby-related variables, the cut-off point for the bottom $5 \%$ of the distribution of apo A-I was $0.21 \mathrm{~g} / \mathrm{L}$ of whole blood and for the top $5 \%$ of apo B levels, $0.46 \mathrm{~g} / \mathrm{L}$; the 95 th percentile for the distribution of the apo B to A-I ratio was 1.3 . For apo(a), the 95 th percentile was $59 \mathrm{U} / \mathrm{L}$ of whole blood.

When neonates in the top $5 \%$ of the apo B to A-I ratio were assessed, $32 \%$ of these babies had apo A-I levels in the bottom $5 \%$ of the apo A-I distribution, and $33 \%$ had apo B levels above the 95 th percentile of the apo B distribution. By contrast, only $4.2 \%$ of neonates in this apo B to A-I ratio subpopulation had apo(a) levels above the 95 th percentile of $59 \mathrm{U} / \mathrm{L}$ of whole blood. This apo(a) subset appeared in $5.7 \%$ of the top $5 \%$ of the apo B distribution and in $5.3 \%$ of the bottom $5 \%$ of the apo A-I distribution. We concluded that, whereas there appeared to be an association between high apo B and low apo A-I levels, apo(a) concentrations were not related to those of either of these apolipoproteins.

\section{DISCUSSION}

Our present study extends our earlier studies, which were confined to neonatal apo B (23), by providing a profile during the first few days after birth of the major apolipoproteins shown to be associated with enhanced cardiovascular risk. It shows that these apolipoproteins can be measured accurately in a drop of blood spotted onto filter paper for easy collection and storage, and that a large number of samples can be processed conveniently and economically. Whereas we (24-26) and others (2830) have already established that apo A-I and B can be measured in the dried blood spot sample by both ELISA and radial immunodiffusion methods, as far as we are aware apo(a) has not previously been estimated in these samples. The RIA we used for apo(a) in dried blood spots reflected accurately venous serum levels (Fig. 1); likewise, ELISA measurements of blood spot apo A-I and B levels accurately reflected venous serum levels and levels obtained by radial immunodiffusion, the standard method for our laboratory at that time.

The striking feature of the distribution of apo(a) in the neonatal period is its close resemblance to that found in adult Caucasian populations. We found it to be markedly skewed; about $25 \%$ of babies had levels either very low or not detectable, whereas a small proportion (1.2\%) had levels that in adult populations are associated with enhanced cardiovascular risk, i.e. levels more than $12.5 \mathrm{mg} / \mathrm{dL}$ in whole blood equivalent to more than 25 $\mathrm{mg} / \mathrm{dL}$ in serum. Furthermore, neonatal apo(a) concentrations were unrelated to sex, birth weight or age at sampling. These results are all consistent with predominant genetic regulation of apo(a) levels and establish that the apo(a) gene can be fully expressed by the 1 st 2 to 5 postnatal days. Labeur et al. (31) have reported a trend toward an increase in serum levels from $\mathrm{d} 0$ to 7 and a further increase to $180 \mathrm{~d}$ postpartum. This was not evident between $\mathrm{d} 2$ and 7 in our series, and a longitudinal study would be required to establish whether or not a trend does occur. It is noteworthy, too, that neonatal apo(a) concentrations were quite independent of those for apo B and A-I.

In contrast to apo(a), apo A-I concentrations were affected by birth weight (negatively) and age at sampling (positively) but were not different for boys and girls. These two variables, birth weight and age at sampling, could account for only $4.1 \%$ of the total variability of blood apo A-I levels for the whole series $(n=$ 1032 ) and $3.5 \%$ for the 919 neonates weighing $2.0 \mathrm{~kg}$ or greater at birth and sampled when 2 to $5 \mathrm{~d}$ of age. The distribution of apo A-I was very close to normal. Storage at $-20^{\circ} \mathrm{C}$ for the first $24 \mathrm{~h}$ after collection and then at $-70^{\circ} \mathrm{C}$ and analysis within $2 \mathrm{wk}$ obviated any confounding effects of storage that can falsely elevate measured apo A-I levels, probably due to oxidation (32).

For apo B also, the possible confounding effects of diminished immunoreactivity with storage at room temperature were obviated. However, in general, the results obtained with the ELISA method mirrored closely those we have previously reported for apo B using the more labor intensive radial immunodiffusion approach (23). Levels were significantly higher in girls, and positively related to birth weight and age at sampling in both sexes. Together these three variables accounted for $4.8 \%$ of the variability; birth weight accounted for $4 \%(n=1032)$. For babies sampled on $\mathrm{d} 2$ to 5 and with birth weights of $2.0 \mathrm{~kg}$ or greater, these three variables accounted for $6.2 \%$ of the variability. Age at sampling had only a small effect $(0.8 \%)$, suggesting that apo B levels are largely stabilized by the 3 rd to 5 th postnatal day. After correcting for these variables, the distribution of apo B levels was strongly skewed, as was found in our earlier study (23), and differed markedly from that of apo A-I. Although both genetic and perinatal factors could be contributing to this difference, there is the possibility of greater variability of apo B gene expression in the 1st week of life. Our earlier follow-up studies of neonates with high levels and their parents would also be consistent with a genetic explanation (33).

The use of computer-determined adjusted values for apo B to establish a cut-off point for recall of infants with high values and their parents should provide a higher yield of genetically determined apo B elevation at retesting. Also, by confining our analysis and recall to babies of birth weight greater than $2.0 \mathrm{~kg}$ sampled on $\mathrm{d} 2$ to 5 , we should be assessing a population much closer to that seen in the general community. Our University maternity hospital is a tertiary referral center with a much higher than average proportion of complicated pregnancies and births and underweight and sick babies, who are usually sampled later than $\mathrm{d} 5$.

After correcting for the variables affecting apo B and apo A-I, the distribution of the apo B/apo A-I ratios was also markedly skewed and appeared to come from two separate populations. Separation was evident before correcting for the baby-related variables but was more evident after correction (Fig. 5). Babies could be separated on the basis of the distribution of apo B alone, but those with high apo B/apo A-I ratios were more clearly separated from the rest of the population. There was, furthermore, some clustering in that approximately $1 / 3$ of those babies who constituted the top $5 \%$ of the ratio of apo B/apo A-I also appeared in the top $5 \%$ of the adjusted apo B distribution; $1 / 3$ also appeared in the lower-most $5 \%$ of the adjusted apo A-I distribution. Interestingly, the ratio for boys and girls was not different. This result is at variance with the higher ratio we reported in boys based on measurements in just 57 neonates (25). This emphasizes the fact that when many variables are influencing neonates, observations in a large number of infants are required before valid conclusions can be drawn. Because the apo B/apo A-I ratio is reportedly a sensitive predictor of cardiovascular risk (34-38), it is of considerable interest to see whether 
a high ratio in a neonate is matched by a high ratio in one parent and possibly other 1 st degree relatives.

In summary, we have developed simple, inexpensive assays for apo B, apo A-I, and apo(a) levels in dried blood spots on filter paper, and used them to describe the differing distribution patterns of these apolipoproteins among 1032 consecutively-born neonates; we have also identified some of the variables affecting levels and quantified their concentrations. By taking account of these variables we have calculated corrected apo B and A-I values with a view to developing arbitrary cut-off points for recall of those with high apo B levels and apo B/apo A-I ratios. We have also examined the distribution, among these groupings, of apo(a) levels elevated above an arbitrary cut-off point used to predict increased coronary risk in adults, and shown that high levels are not correlated with either high apo B levels or with high apo B/apo A-I ratios in this neonatal population.

The information gained expands knowledge of the behavior of these apolipoproteins in the neonatal period and documents the extent of the expression of the apo(a) gene in the first few days of life. The latter results are in accordance with the predominance of genetic regulation of apo(a). Appropriate follow-up of identified families should determine whether or not these data could be used to improve prospects for detecting families at enhanced cardiovascular risk.

Acknowledgments. The authors thank the staff of the New South Wales Newborn Screening Program and the Royal Hospital for Women for the opportunity to do the study, Ian Botten and Sister Judith Materna for help in collecting the specimens, and Pharmacia (Australia) Pty. Ltd. for technical advice.

\section{REFERENCES}

1. Strong JP, Newman III WP, Freedman DS, Gard PD, Tracy RE, Solberg LA 1986 Atherosclerotic disease in children and young adults: relationship to cardiovascular risk factors. In: Berenson GS (ed) Causation of Cardiovascular Risk Factors in Children: Perspectives on Cardiovascular Risk in Early Life. Raven Press, New York, pp 27-41

2. Stary HC 1989 Evolution and progression of atherosclerotic lesions in coronary arteries of children and young adults. Arteriosclerosis 9(suppl 1): I19-I32

3. Berenson GS, Srinivasan SR, Wattigney W, Webber LS, Newman III WP, Tracy RE 1989 Insight into a bad omen for white men: coronary artery disease-The Bogalusa Heart Study. Am J Cardiol 64:32C-39C

4. Bachorik PS, Kwiterovich $\mathrm{J} r$ PO 1988 Apolipoprotein measurements in clinical biochemistry and their utility vis-a-vis conventional assays. [review] Clin Chim Acta 178:1-34

5. Berg K, Dahlen G, Frick MH 1974 Lp(a) lipoprotein and pre- $\beta_{1}$-lipoprotein in patients with coronary heart disease. Clin Genet 6:230-235

6. Hoefler G, Harnoncourt F, Paschke E, Mirtl W, Pfeiffer KH, Kostner GM 1988 Lipoprotein Lp(a). A risk factor for myocardial infarction. Arteriosclerosis 8:398-401

7. Scanu AM 1989 Lipoprotein(a). Twenty-five years of progress. Arteriosclerosis 9:565-566

8. Rath M, Niendorf A, Reblin T, Dietel M, Krebber H, Beisiegel V 1989 Detection and quantification of lipoprotein(a) in arterial wall of 107 coronary bypass patients. Arteriosclerosis 9:579-592

9. Cushing GL, Gaubatz JW, Nava ML, Burdick BJ, Bocan TMA, Guyton JR, Weilbaecher D, DeBakey ME, Lawrie GM, Morrisett JD 1989 Quantitation and localization of apolipoprotein(a) and B in coronary artery bypass vein grafts resected at reoperation. Arteriosclerosis 9:593-603

10. Utermann G 1989 The mysteries of lipoprotein(a). Science 246:904-910

11. Rosenfeld L 1989 Atherosclerosis and the cholesterol connection: evolution of a clinical application. Clin Chem 35:521-531

12. Goodman DS 1989 Cholesterol revisited. Molecule, medicine, and media Arteriosclerosis 9:430-438
13. Kannel WB 1988 Cholesterol and risk of coronary heart disease and mortality in men. Clin Chem 34:B53-B59

14. Havel RJ 1988 Lowering cholesterol, 1988. Rationale, mechanisms, and means. J Clin Invest 81:1653-1660

15. Manninen V, Elo MO, Frick MH, Haapa K, Heinonen DP, Heinsalmi P, Helo P, Huttunen JK, Kaitaniemi P, Koskinen P, Maenpaa H, Malkonen M, Manttari M, Norola S, Pasternack A, Pikkarainen J, Romo M, Sjohlom T, Nikkila EA 1988 Lipid alteration and decline in the incidence of coronary heart disease in the Helsinki heart study. JAMA 260:641-651

16. The Expert Panel 1988 Report of the National Cholesterol Education Program Expert Panel on detection, evaluation, and treatment of high blood cholesterol in adults. Arch Intern Med 148:36-69

17. Consensus Conference 1985 Lowering blood cholesterol to prevent heart disease. JAMA 253:2080-2086

18. British Cardiac Society Working Group on Coronary Prevention 1989 Conclusions and recommendations. Br Heart J 57:188-189

19. Leitch D 1989 Who should have their cholesterol concentrations measured? Br Med J [Clin Res] 298:1615-1616

20. American Academy of Pediatrics, Committee on Nutrition 1989 Indications for cholesterol testing in children. Pediatrics 83:141-142

21. Griffin TC, Christoffel KK, Binns HJ, McGuire PA, Pediatric Practice Research Group 1989 Family history evaluation as a predictive screen for childhood hypercholesterolemia. Pediatrics 84:365-373

22. Dennison BA, Kikuchi DA, Srinivasan SR, Webber LS, Berenson GS 1989 Parental history of cardiovascular disease as an indication for screening for lipoprotein abnormalities in children. J Pediatr 115:186-194

23. Blades BL, Dudman NPB, Wilcken DEL 1987 Variables affecting apolipoprotein B measurements in 3- to 5-day-old babies: a study of 4491 neonates. Pediatr Res 21:608-614

24. Wang XL, Dudman NPB, Blades BL, Wilcken DEL 1989 Changes in the immunoreactivity of apo A-I during storage. Clin Chim Acta 179:285-294

25. Wang XL, Dudman NPB, Wilcken DEL 1989 Enzyme-linked immunosorbent assay of apolipoprotein B in blood spotted onto filter paper, suitable for neonatal screening. Clin Chem 35:1000-1004

26. Dudman NPB, Blades BL, Wilcken DEL, Aitken JM 1985 Radial immunodiffusion assay of apolipoprotein B in blood dried on filter paper-a potential screening method for familial type II hypercholesterolaemia. Clin Chim Acta 149:117-127

27. Pharmacia Diagnostics 1988 Pharmacia apolipoprotein(a) RIA 100. [directions for use] Uppsala, Sweden

28. Rosseneu M, Van Biervliet JP 1985 Screening and follow-up of infants with dyslipoproteinemia. Prog Clin Biol Res 188:79-86

29. Micic S, Arends J, Norgaard-Pedersen B, Christoffersen K, Andersen GE 1988 Simultaneous quantification by double rocket immunoelectrophoresis of apolipoproteins A-I and B in blood spotted on filter paper. Clin Chem $34: 2452-2455$

30. Ohta T, Migita M, Yasutake T, Matsuda I 1988 Enzyme-linked immunosorbent assay for apolipoprotein $\mathrm{B}$ on dried blood spot derived from newborn infant: its application to neonatal mass screening for hypercholesterolemia. J Pediatr Gastroenterol Nutr 7:524-531

31. Labeur C, Michiels G, Bury J, Usher DC, Rosseneu M 1989 Lipoprotein(a) quantified by an enzyme-linked immunosorbent assay with monoclonal antibodies. Clin Chem 35:1380-1384

32. Wang XL, Dudman NPB, Wang J, Wilcken DEL 1989 Mechanisms responsible for increasing immunoreactivity of apolipoprotein A-I with storage: the role of oxidation. Clin Chem 35:2082-2086

33. Blades BL, Dudman NPB, Wilcken DEL 1988 Screening for familial hypercholesterolemia in 5000 neonates: a recall study. Pediatr Res 23:500-504

34. Van Stiphout WAHJ, Hofman A, Kruijssen HACM, Vermeeren R, Groot PHE 1986 Is the ratio of apo B/apo A-I an early predictor of coronary atherosclerosis? Atherosclerosis 62:179-182

35. Kukita H, Hiwada K, Kokubu T 1984 Serum apolipoprotein A-I, A-II and B levels and their discriminative values in relatives of patients with coronary artery disease. Atherosclerosis 51:261-267

36. Kwiterovich Jr PO, Sniderman AD 1983 Atherosclerosis and apolipoprotein A-I and B. Prev Med 12:815-834

37. Brunzell JD, Sniderman AD, Albers JJ, Kwiterovich Jr PO 1984 Apolipoprotein B and A-I and coronary artery disease in humans. Arteriosclerosis 4:7983

38. Trejo-Gutierrez J, Derby C, Pearson T, Achuff S, Smith H 1987 The ratio of apoprotein $\mathrm{B}$ to apoprotein A-I as the best predictor of premature coronary artery disease in women. J Am Coll Cardiol 9:54A(abstr) 